Archived version from NCDOCKS Institutional Repository http://libres.uncg.edu/ir/asu/

\title{
Appalachlyan
}

B O O N E, NORT H C A R O L N A

\section{Medieval Literature On Display}

\author{
By: Alexandra Sterling-Hellenbrand
}

\begin{abstract}
Medieval Literature on Display is a monograph (currently in press with Bloomsbury, publication date of January 2020) on the role of medievalism in practice of cultural memory and the creation of heritage. The book focuses on two case studies from the time immediately following the reunification of Germany in 1990. Both case studies involve German museums dedicated to medieval literature: the first is the Museum Wolfram von Eschenbach in Wolframs- Eschenbach (1995); the second is the Nibelung Museum in Worms (2001). Largely unknown to wider audiences outside of their geographic regions, these museums deserve greater attention. They reveal how memory, through the lens of the Middle Ages, shapes modern cultural identity and heritage.
\end{abstract}

Sterling-Hellenbrand, A. (2019). Medieval Literature on Display. RECAPP 2019, The Office of Research. NC Docks permission granted by author. 
Medieval Literature on Display

Alexandra Sterling-Hellenbrand

Professor of German and Global Studies

Department of Languages, Literatures and Cultures

25 October 2019

Medieval Literature on Display is a monograph (currently in press with Bloomsbury, publication date of January 2020) on the role of medievalism in practice of cultural memory and the creation of heritage. The book focuses on two case studies from the time immediately following the reunification of Germany in 1990. Both case studies involve German museums dedicated to medieval literature: the first is the Museum Wolfram von Eschenbach in WolframsEschenbach (1995); the second is the Nibelung Museum in Worms (2001). Largely unknown to wider audiences outside of their geographic regions, these museums deserve greater attention. They reveal how memory, through the lens of the Middle Ages, shapes modern cultural identity and heritage.

Medieval Literature on Display demonstrates how the modern communities of Worms and Wolframs-Eschenbach use medievalism in the modern task of making the past present through their displays of German medieval literature as heritage. The case studies show the museums as creative attempts to make the middle ages relevant, even profitable, for local municipalities. Close scrutiny of the processes involved can be used to better understand the cultural productions of other local and regional communities involved in similar projects to reconstruct their past, medieval or otherwise.

This book contributes to contemporary conversations about medievalism's role in constructing and affirming cultural identity; in sum, it is a volume on how we conceptualize and find places for the future of the past. A corollary project on medievalism in Austria will be supported by a Fulbright grant in spring 2020. 
This book also sits at what I hope is an equally vibrant intersection. Before we go any further, however, I must confess that I realize it is probably much easier to describe what this book is not. It is not a book on museum studies, though it does focus on two museums, nor on literary museums, per se- though the two museums at the book's center put literature on display. It is not a book on heritage studies, though it does examine these museums as examples of heritage making in two German communities. It is not quite a book on reception history of medieval German literature, though reception plays a key role in how the literature is adapted over time. It is not quite a book on medieval studies, not at least as I learned the tools of what I might consider the traditional discipline in the 1990s. This book does occupy an interface where it draws from all of these areas in order to examine two German museums that express the aspirations of their respective municipalities in the display of medieval texts with particular significance for each community. Each museum is unique, as is each community. The museums are similar, however, in their display of medieval literature as part of the communal past that shapes the present toward the future. This book is about giving literature and ideas tangible form, about making the past present, about connecting the medieval to the contemporary. Like the museums it explores, this book is, I believe, an example of medievalism at work.

There are several interlocking concepts that we need to identify, clarify, and briefly define in the context of this project. First, we will return in more detail to the concept of past presencing in order to frame more broadly the other key terms that constitute the theoretical framework of Medieval Literature on Display. First, we will address memory as the primary mechanism, whereby we make the past present. The work of memory is deeply embedded in the medieval literature the museums put on display; it also prompted the modern need to design the museum. Medievalism is the process of presencing the medieval past in the contemporary 
present. Nostalgia plays a significant role in the process of medievalism; described most simply as a longing for the past in the present, we might see it as a powerful force that often drives the dynamic process of medievalism with its need for presencing the past. Nostalgia locates, amplifies, and intensifies memory. Memory takes material form in heritage. The concept of heritage straddles the immaterial and the material, the intangible and the tangible, the abstract and the concrete. Each of these concepts (memory, medievalism, nostalgia, heritage) has been researched extensively; I cannot do justice to it all, except to acknowledge my own debt to that scholarship in my focus on the museums at the heart of Medieval Literature on Display. The museums touch facets of each concept as they reconfigure their respective medieval texts for the present, giving them material form. In the Museum Wolfram von Eschenbach and in the Nibelung Museum, medievalism drives memory in the creation of new heritage through a unique and an intentional emplacement of the medieval literary past in the landscape and architecture of the present. Monuments resonate with ideas and metaphors, containing and perpetuating collective memory over time for the communities in which they are located. People imbue them with meaning, meaning that can be shaped and adapted over time as memory becomes part of real lived experience.

The desire to share and to preserve lived experience brings us back to the general project of museums; as suggested earlier, musealization is one way in which modern European culture is dealing with memory now, especially since the end of the twentieth century. In Memorylands, Macdonald describes the wide-ranging responses to the identity issues that have emerged since the fall of the Berlin Wall in 1989-these responses are presented in various kinds of museal display. As Macdonald uses the term, a "memoryland" may refer to a particular geographic location. The term may include physical monuments or it may describe a more abstract 
landscape, a set of objects or even behaviors that reflect a personal or collective approach to or experience of the past. Aesthetic or imaginative reactions to past time also shape these memorylands, emerging through the process of past presencing. Memorylands shape the contours of our relationships to past, present, and future not just as individuals but also as communities. They form what Macdonald calls the European memory complex; this describes the wide spectrum of ways in which that memory complex manifests itself in the contemporary cultural landscape: seeing, telling, feeling, showing the past. This is the on-going process of past presencing that encompasses the many ways in which the past is continually reconfigured in a changing present. The term "is intended to draw attention to the multiple ways in which the past may be (and be made to be) present- — as well as represented-- — whether articulated verbally or experienced and performed in other ways." As we see the past in architecture, tell the past in story, feel the past in an old coat, and show the past in a museum, we incorporate the past into our present.

From our vantage point in the present, we now look back at the Middle Ages; however, we know our medieval counterparts looked back as well. Medieval texts form the deep center of this book. Medieval cultures were unquestionably memorial cultures, and thus memory significantly shaped the literature our museums put on display; this has been firmly established by the work of a number of scholars since 1990, most notably Mary Carruthers in her groundbreaking study The Book of Memory. Memory is a dynamic, interactive, and performative process.

The museums in Worms and Wolframs Eschenbach support interactions of place and memory that drive the presencing of the past in their communities. When we visit Wolframs Eschenbach or Worms now, we find medieval literature firmly ensconced in the cityscapes. Each 
museum makes a unique contribution to the European memory complex by literally placing literature at the center of its display in a creation of new-old heritage.

This nexus of medieval literature, cultural memory, and local history stages a captivating encounter with the past that resonates in the present that we, collectively and individually, inhabit. The museums want the public to come and visit, to enjoy the installations, to reflect on a larger message. They also urge us to respond. Indeed, in the future, I hope that in the future, they do more to confront and to unsettle and to challenge their visitors. I think the museums clearly intend (as Macdonald suggests of heritage in Europe generally) "to unsettle - to dislodge us from our comfort zones" as we confront the heritage of the narrative past. The materiality of heritage, on this local level, may indeed become that "potentially compelling" dimension of cultural policy that will assist in cultivating an educated citizenry. Whether the municipal or museum administrators aim that high, I believe that these "local" museums do achieve a global resonance in their presentation and interpretation of older narratives for contemporary audiences; the medieval narrative past becomes living present. The medievalism of the museums in Worms and Wolframs Eschenbach therefore not only provides a model for other communities to participate in the European memory complex. The museums, like medievalism, allow us to imagine new directions as we continue to explore a future for the past Medieval Literature on Display: Heritage and Culture in Modern Germany (Bloomsbury 2020_ this was in press when the presentation was given)

Introduction: A Statue and a Story

1. Medievalism and Memory

2. Adapting Medieval Narratives 
3. A Knight at the Museum:

Medieval Literature and/as Local Heritage at the Museum Wolfram von Eschenbach

4. The Machinery of Myth:

The Nibelung Museum and the Interrogation of Cultural Memory

5. Presencing the Narrative Past:

Old Structures, New Stories?

6. The Future of the Past:

Medieval Literature on Display 


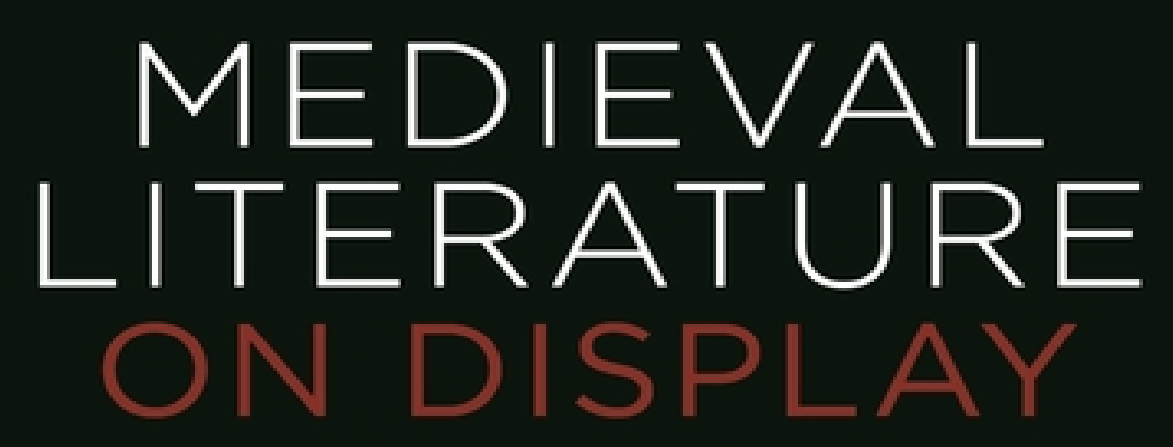

Heritage and Culture in Modern Germany

Alexandra Sterling-Hellenbrand Professor of German and Global Studies Department of Languages, Literatures and Cultures 25 October 2019

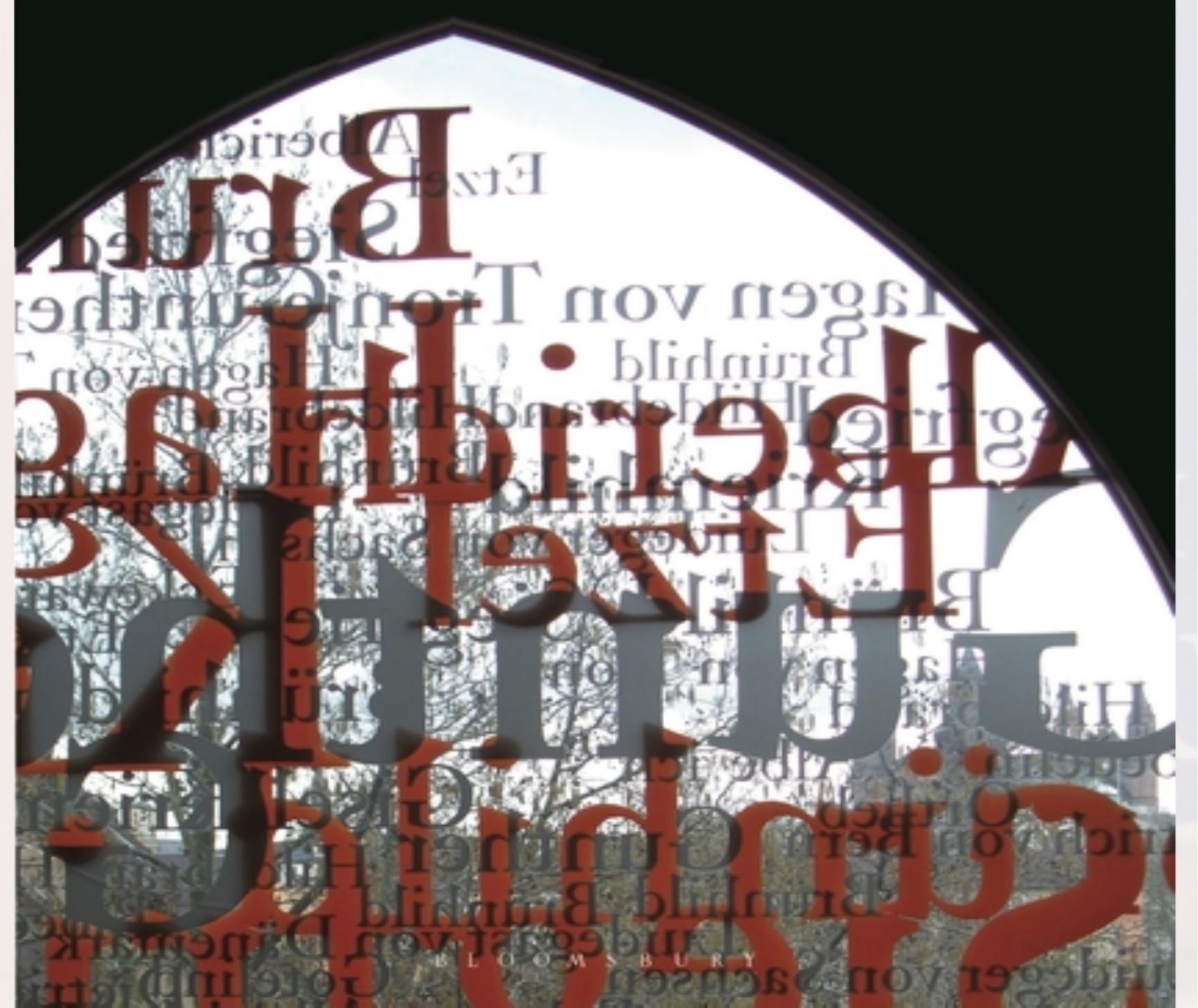




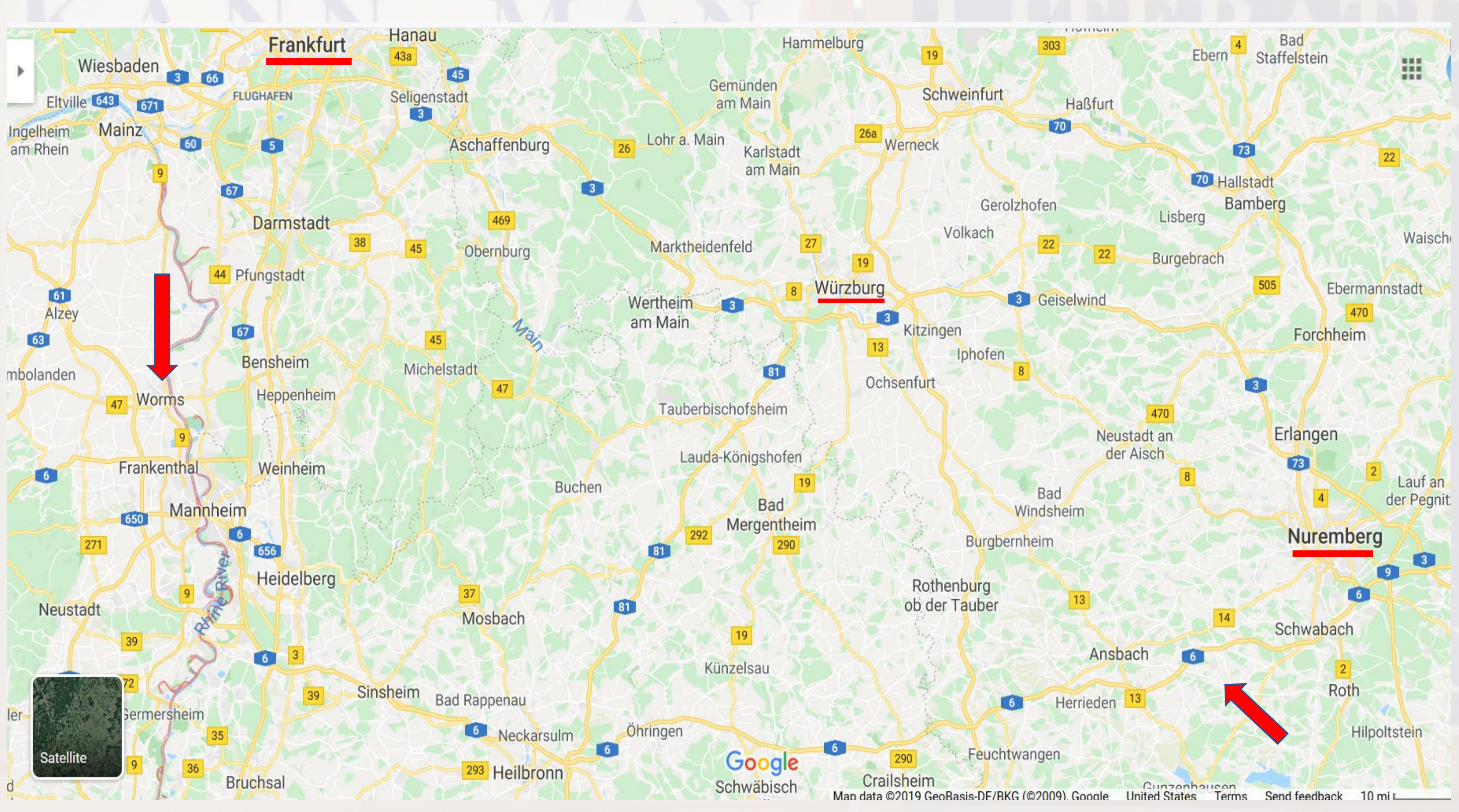




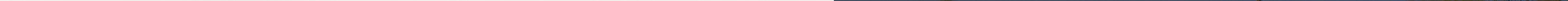


Kann man Literatur ausstellen? Can literature be displayed? 

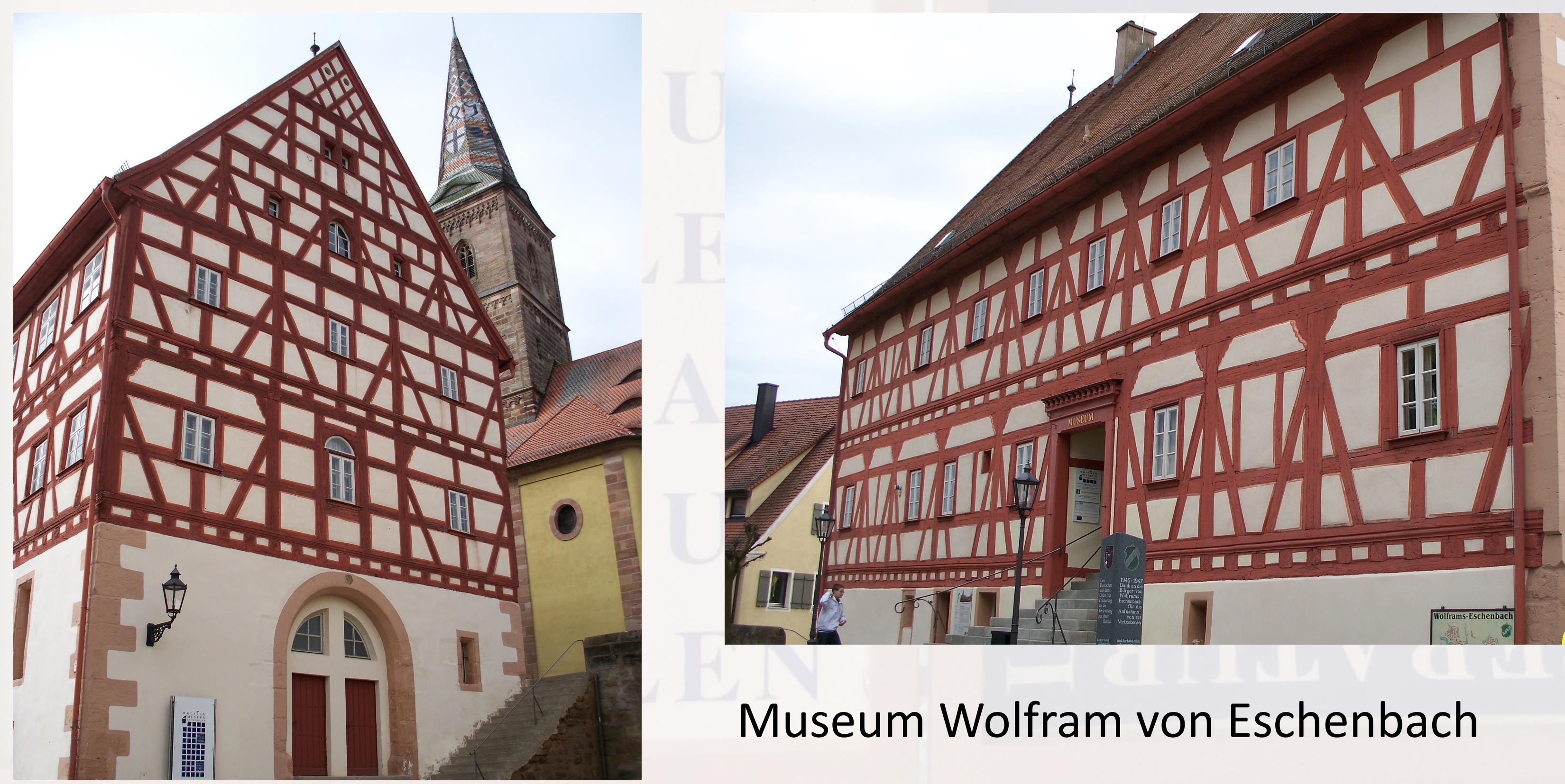

Museum Wolfram von Eschenbach 


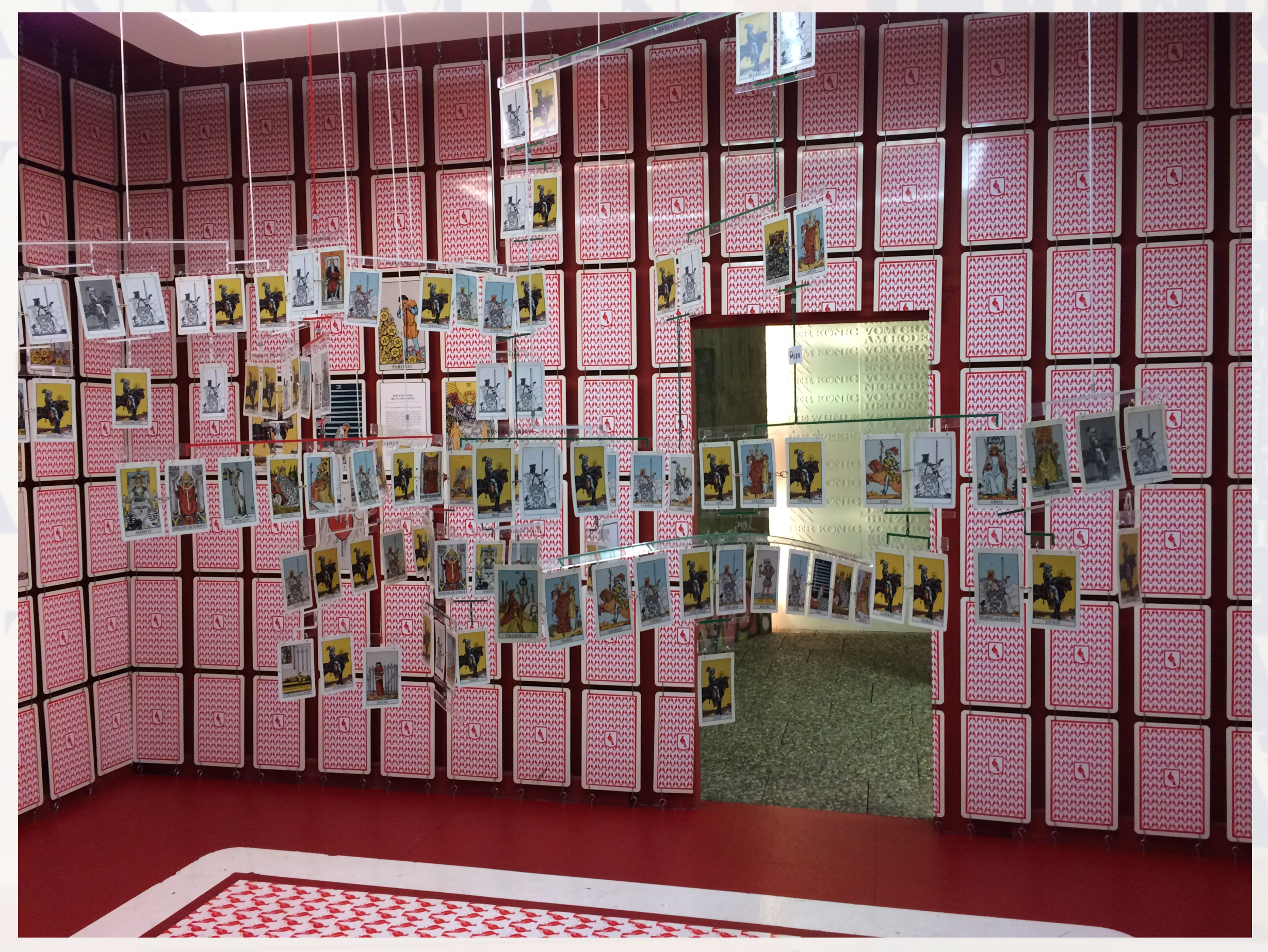



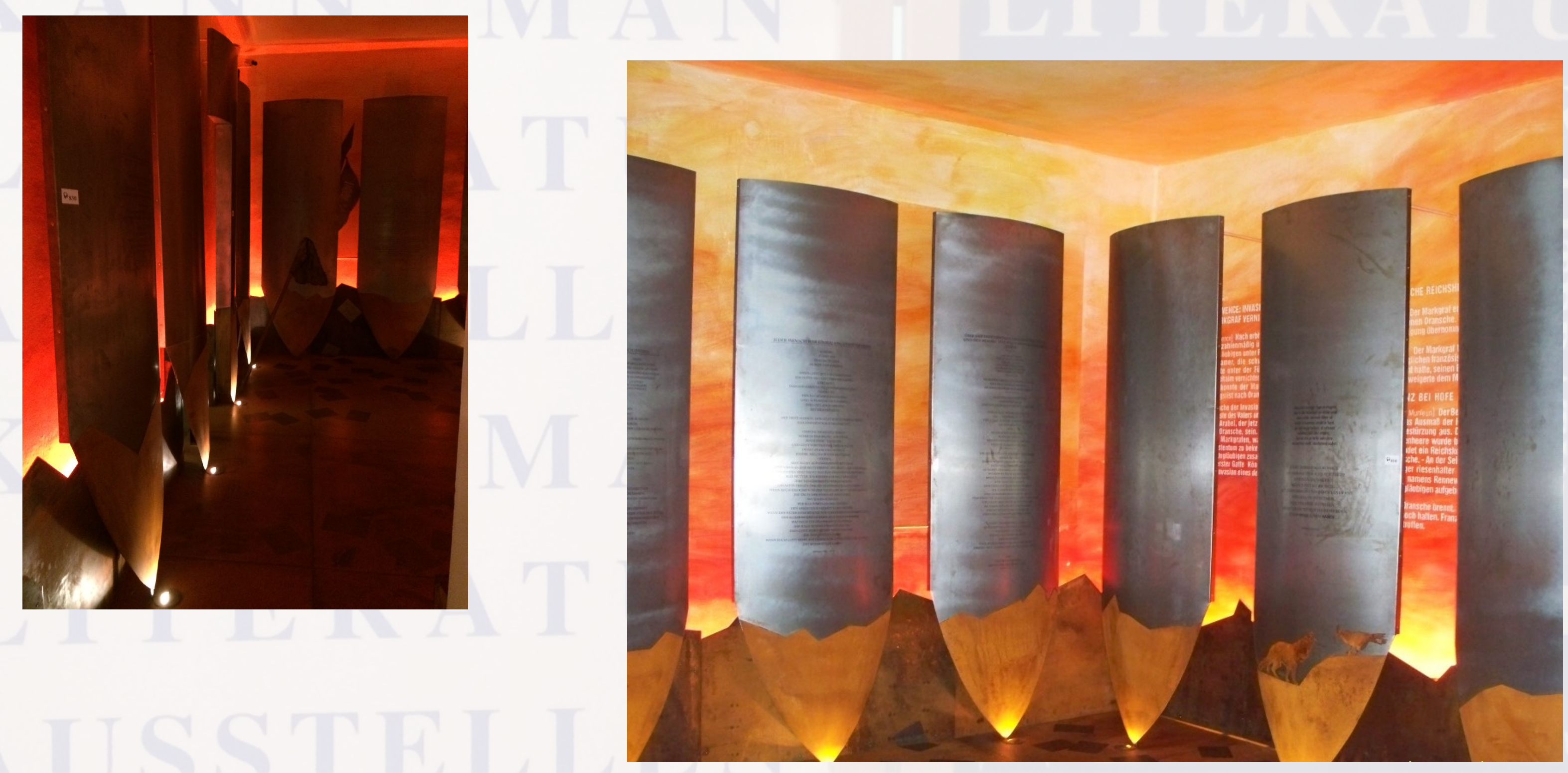


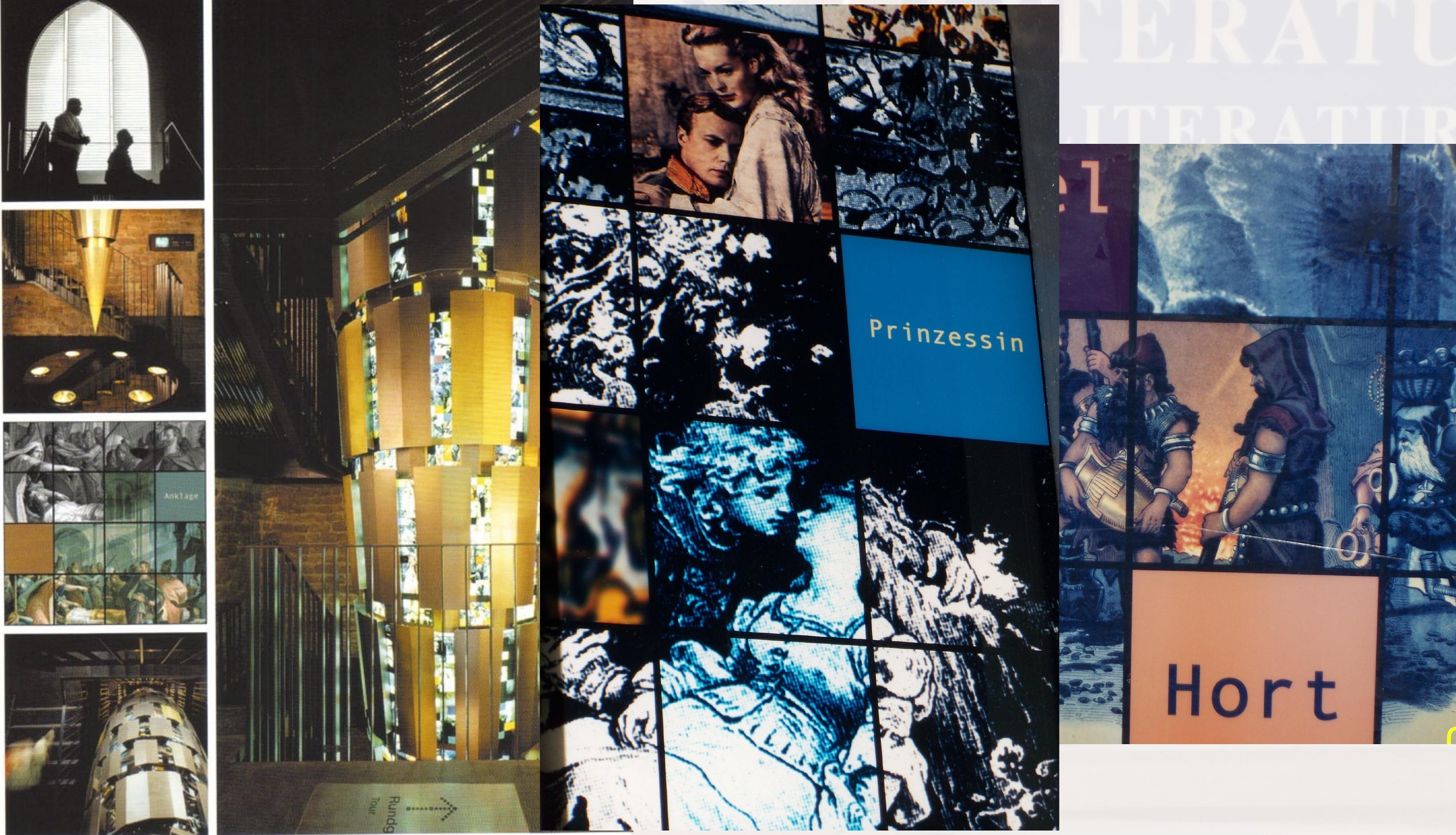




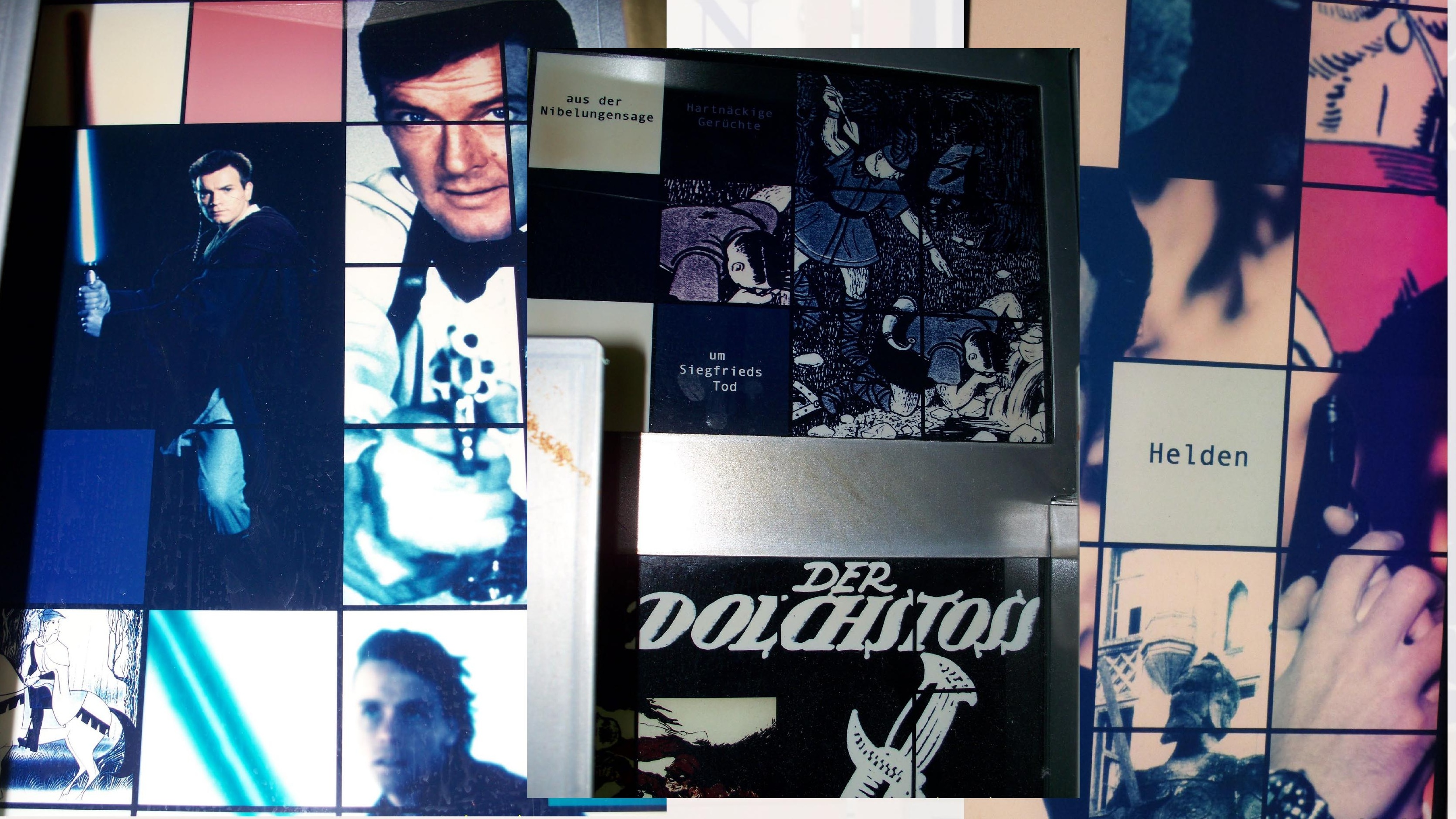


